\title{
Healthy aging as disease?
}

\section{Ruth Elaine Nieuwenhuis-Mark*}

Department of Medical Psychology and Neuropsychology, Tilburg University, Tilburg, Netherlands

*Correspondence: r.e.mark@uvt.nl

In the scientific and popular literature recently there has been a widespread call for classifying normal aging as a disease, a condition that can be "manipulated, treated, and delayed” (Gems, 2010; Kelland, 2010). The main argument given by supporters of this suggestion is that grant-awarding bodies would be more likely to fund research into how, when, and why we age, and that doctors would become duty-bound to treat it (Kelland, 2010). However, it has recently been suggested that there is actually a chronic underinvestment in Alzheimer's disease research (Cassels, 2010). Why then, would relabeling normal old age a disease suddenly increase funding in fundamental aging research when money is hard enough to come by for research into $\mathrm{AD}$ ? A recent study investigated the genetic profiles of centenarians and claimed evidence for "Methuselah genes" which enable certain people to live to 100 and beyond (Sebastiani et al., 2010). Predictions suggest that tests for these gene-driven traits will be commercially available in 2-5 years (Rogers, 2010). There is therefore a move among geneticists and gerontologists toward treating normal old age as a health issue, and, as Dr. David Gems, a biogerontologist at UCL, suggests "We need to reclassify it [aging] as a disease rather than as a benign, natural process" (Gems, 2010). Indeed, many of the most devastating of the world's diseases, namely diabetes, heart disease, cancer, and dementia all have aging as a common mechanism in the sense that they tend to become more problematic and thus costly as sufferers age.

The word "disease" has of course more negative connotations than positive. In most dictionary definitions words like "pathology" and "impairment" are used. The main problem of adopting the aging-as-disease viewpoint is that it surely strengthens the already negative stereotype which hangs around aging: that of the depressed, lonely elder who can only look forward to increasing health problems as the years go by
(Sneed and Whitbourne, 2005). Instead of aging being seen as a normal process we all must go through (unless we die young) disease supporters want us to view it as something which can and must be prevented. Yet, the truth is that many elderly people live fulfilling lives and successful aging is more the norm than the exception, while at the same time individual differences in coping style, personality, cognitive functioning, and motivation are widespread. And therein lies the rub: if normal aging is classified as a disease process will it not make aging more feared and reviled than it already is?

A popular theory in the aging literature since the early 1990s is the socioemotional selectivity theory (SST; Carstensen, 1992). SST was put forward as an attempt to explain the so-called "paradox of aging" which refers to the finding that while physical health tends to decline as we age subjective well-being may be maintained or even improve (Diener and Suh, 1998). At the heart of SST is time perspective, with elderly people said to be present- rather than future-focused, and that they are motivated to maximize positive experiences, minimize the negative, and spend quality-time with loved ones in smaller social networks. Focusing on normal aging as a disease could therefore be seen as a step-back for aging research rather than a move forward. Agingas-disease proponents would argue however that their focus is on improving quality of life in our final years, not on increasing our lifespans per se.

Alzheimer's dementia is set to become the number one concern of health professionals and carers as populations worldwide age due to its direct link with advancing age (Kelland, 2010). Whether we can make the jump from $\mathrm{AD}$ to all aging as disease is however, at the very least, questionable, and indeed, worrisome. Do we really need to feed the already negative stereotypes which exist of the elderly in society? Should we not be celebrating how much the old bring to the world and have still to offer not only to close family and friends but also to society at large? Indeed, author Strauch (2010) suggests in her recent book that people underestimate the many talents of the mature brain and that it reaches its peak performance between the ages of 40 and 68 . There are also calls for raising the pension age across Europe in recognition of the fact that people are not "finished" when they hit 65 , that they can still be productive, worthwhile. Labeling aging as a disease may or may not help research funding but it can only hurt public opinion of what it means to age.

\section{REFERENCES}

Carstensen, L. L. (1992). Social and emotional patterns in adulthood: support for socioemotional selectivity theory. Psychol. Aging 7, 331-338.

Cassels, C. (2010). Alzheimer's researchers hit the road to bring attention to national funding crisis. Medscape Medical News. Available at: www.medscape.com/ viewarticle/725178_print (accessed July 22, 2010).

Diener, E., and Suh, M. E. (1998). "Subjective well-being and age: an international analysis," in Annual Review of Gerontology and Geriatrics: Focus on Emotion and Adult Development, Vol. 17, eds K. W. Schaie and M. P. Lawton (New York: Springer), 304-324.

Gems, D. (2010). Quoted in: Found: Genes That Let You Live to 100, Environment Editor, Jonathan Leake (Sunday Times, 4 th July). News Section.

Kelland, K. (2010). Is Aging a Disease? London: Reuters. Rogers, L. (2010). Live fast but die old. Focus Article, The Sunday Times, 4 th July.

Sebastiani, P., Solovieff, N., Puca, A., Hartley, S. W., Melista, E., Andersen, S., Dworkis, D. A., Wilk, J. B., Myers, R. H., Steinberg, M. H., Montano, M., Baldwin, C. T., and Perls, T. T. (2010). Genetic signatures of exceptional longevity in humans. Science. doi: 10.1126/science.1190532. [Epub ahead of print].

Sneed, J. R., and Whitbourne, S. (2005). Models of the aging self. J. Soc. Issues 61, 375-388.

Strauch, B. (2010). The Secret Life of the Grown-up Brain: The Surprising Talents of the Middle-Aged Mind. New York: Viking Press.

Received: 02 August 2010; accepted: 11 February 2011; published online: 22 February 2011.

Citation: Nieuwenhuis-Mark RE (2011) Healthy aging as disease? Front. Ag. Neurosci. 3:3. doi: 10.3389/ fnagi.2011.00003

Copyright (C) 2011 Nieuwenhuis-Mark. This is anopen-access article subject to an exclusive license agreement between the authors and Frontiers Media SA, which permits unrestricted use, distribution, and reproduction in any medium, provided the original authors and source are credited. 